\title{
Wellcome sets sequencing project in motion
}

London. Britain's Wellcome Trust has become the first funding agency on either side of the Atlantic to commit firm support for a plan to produce a full-length 'low-pass' sequence of the complete human genome by the year 2002.

As government funding agencies in the United States and the United Kingdom struggle to find the money they hope to raise for such a project, Wellcome announced last week that it had agreed to provide sufficient financial support to the Sanger Centre, at Hinxton Hall near Cambridge, to sequence one-sixth of the genome.

No precise figure has been given. But in a statement, Wellcome says that the money should be sufficient to enable the Sanger Centre to identify at least 500 million of the 3 billion base-pairs in the genome at an eventual estimated cost of less than $£ 0.10$ a base pair, giving a minimum figure of $£ 50$ million (US\$80 million).

Wellcome is by far the largest biomedical charity in Britain, with a $£ 200$-million annual budget close to that of the Medical Research Council (MRC), and the money will be additional to funds originally committed to setting up the centre - named after Frederick Sanger, who has twice won the Nobel prize for chemistry - jointly with the MRC.

The total plan aims to cover about 95 per cent of the complete genome sequence with an accuracy of more than 99.9 per cent. It was hatched last year by John Sulston, head of the Sanger Centre, and Bob Waterston, of Washington University in St Louis, Missouri, with whom Sulston has worked on the sequencing - now nearing completion - of the genome of the nematode worm Caenorhabditis elegans.

After some initial scepticism, a consensus appears to have emerged among molecular biologists that recent mapping achievements - as well as indications that no major advances in sequencing technology can be expected in the near future - suggest that the time has come for an attack on the complete human genome.

Sulston says he is keen that the project should be truly international, with strategy determined by the participating groups rather than by their funding agencies. "This is not a race; we are open to any type of cooperation [with other laboratories] or splitting up of the genome," he says.

Reflecting this approach, Sulston and Waterston felt the optimal division of labour was for one-third of the sequence to be determined by the Sanger Centre, one-third perhaps in Waterston's laboratory, and onethird by other participating laboratories.

Interested US laboratories are now awaiting the result of reviews of more than 20 applications received in response to a request for proposals sent out earlier this year by the National Center for Human
Genome Research (NCHGR) of the National Institutes of Health (NIH).

Final decisions are expected early next year. But there is still some uncertainty about how much money will be available. Although additional funds for megasequencing projects have been sought by the Clinton administration in its NIH budget request for the fiscal year which started on 1 October - and have been given priority by Congress during lengthy budget negotiations - final details have yet to be agreed.

NCHGR officials say they are optimistic that the money will be found one way or another. Indeed, they claim that enough progress has been made on mapping projects to make possible the reallocation of sufficient funding within its \$114-million annual budget to meet the sequencing requests, even if no new budget figure is agreed and the NIH remains funded on the basis of a continuing resolution.

In Britain, there is similar uncertainty over the money promised, at least informally, by the MRC. Earlier this year, in releasing the science budget for the financial year

1995-96, the government announced that this would include a special item of $£ 9.6$ million for genome research and immunology. But beyond a commitment of $£ 2$ million to complete the $C$. elegans work, no announcement has yet been made of what type of long-term commitment the MRC may make to human genome sequencing.

The Wellcome Trust hopes that last week's announcement, which it says will allow the Sanger Centre to "spearhead" the international sequencing programme, will help to catalyse efforts elsewhere, and is keen that the resulting sequence should be in the public domain.

According to Sulston, the precise division of labour will be determined by the interests of the laboratories that eventually agree and are funded - to participate, but is likely to be based on different institutions taking responsibility for different chromosomes.

Sulston says that Wellcome is planning to organize a meeting next year of the major laboratories involved in the area to discuss questions of strategy. "We want to share the leadership," he says.

David Dickson

\section{Genetic testing 'needs more checks'}

San Francisco. US academic and commercial laboratories are rushing to offer genetic testing with a minimum of external review, according to a new survey that reinforces concern among geneticists about the quality of laboratory testing in the United States, as well as the interpretation of results.

The results of the survey led to demands from scientists at the annual meeting of the American Society of Human Geneticists in Minneapolis, Minnesota, last week for a system to evaluate the accuracy and interpretation of tests, as well as turn-around times.

One academic geneticist cited a commercial laboratory that had taken a year to provide test results - and even then had missed two mutations that she had already identified. Others claimed that federal regulations on laboratory quality fail to address the specific technology involved in genetic testing. Furthermore, institutional review boards, which tend to be responsible for evaluating the quality of tests offered as part of a research project, may not have any background in genetics.

Rebecca Anderson, chair of the genetic services committee of the National Society of Genetic Counsellors, said she has great confidence in most laboratories, but would like to see proficiency tests in place. More difficult, she said, may be problems of interpretation of the tests, especially by primary care physicians.

Other geneticists warned of a particular danger in the tendency to use information about high-risk families to make predictions about the general population. Launching population screening for diseases such as cancer or Alzheimer's without more quantitative data about the prevalence of certain mutations would produce only "garbage" information. "It doesn't mean we stop. We just have to be very careful," said Michael Watson, a medical geneticist at Washington University School of Medicine in St Louis, Missouri, and head of the laboratory practices committee for the American College of Medical Genetics.

Another specific concern is the use of genetic tests on children. In general, geneticists have agreed not to carry out such tests on minors unless they are likely to benefit directly. But a group of researchers led by Dorothy Wertz at the Shriver Center in Massachusetts surveyed 186 laboratories listed in Helix, a national directory of DNA diagnostic laboratories, and found a high proportion that tested healthy children.

Results of a survey of academic and commercial laboratories that are developing or offering genetic tests on an experimental basis were presented by Neil Holtzman of Johns Hopkins Medical Institutions in Baltimore, Maryland. The study is intended to inform the work of the Task Force on Genetic Testing for the Human Genome Project, which is developing guidelines for the scientific validation of genetic tests, the assurance of laboratory quality and general education and counselling.

Out of 54 biotechnology companies in the survey that said they were developing genet- 
ic tests, 41 per cent had never contacted either the Food and Drug Administration (FDA) or their own institutional review board (IRB). Similarly, out of 140 academic laboratories, more than a quarter had never contacted either organization.

Holtzman pointed out that organizations that provide services and make their own probes and primers must ask for review from their IRB, and in some cases must also obtain an investigational device exemption from the FDA. External review did increase among the 14 biotechnology companies offering services using their own products. But almost 30 per cent still had never contacted a regulatory body.

The study also showed that academic laboratories were less likely than companies to have undergone any external quality review. Out of about a hundred non-profit laboratories providing molecular genetic services, 16 had not registered as required under the federal Clinical Laboratory Improvement Amendments or participated in any proficiency testing. At least one geneticist said he felt his published discoveries were sufficient to demonstrate the quality of his laboratory, and that certification was unnecessary, says Holtzman.

Some participants at the Minneapolis meeting claimed that the survey was too imprecise to demonstrate the size of the problems described. They criticized the results for not indicating how far along the development process a company had progressed before approaching any regulatory body. Stephen Goodman, of the University of Colorado Health Sciences Center in Denver and treasurer of the American Society of Human Genetics, said that a laboratory was not necessarily in the wrong if it had not approached its institutional review boards. "You really need to know the research they're doing," he said. Sally Lehrman

\section{NASA staff face shake-up as panel backs privatization bid}

Washington. The concept of privately run "science institutes" has been endorsed in an internal study at the US Aeronautics and Space Administration (NASA). The institutes would conduct a significant amount of the agency's research and - presumably inherit many of its staff scientists.

But the plan is still vague, and fraught with legal and administrative problems. Scientists inside and outside the agency are reserving judgement until they hear more about it. "We're all still waiting to see the details," says Anneila Sargent of the California Institute of Technology, chair of NASA's Space Science Advisory Council, which will be briefed on the plan next week.

The idea of science institutes surfaced last winter during a series of soul-searching reviews intended to lead to a new, leaner space agency (see Nature 374, 107; 1995).

Initially, 'privatizing' NASA's science was seen as a way to cut the agency's operational overheads. But by the time Daniel Goldin, the NASA administrator, announced a plan to restructure the agency in May, the institutes were no longer being touted as moneysavers but as a way to enhance the quality of NASA research by strengthening its ties with industry and the academic world.

A team led by Al Diaz, the agency's deputy science chief, spent much of the summer touring NASA and non-NASA centres, formulating a plan of the way in which the institutes would be structured. Diaz is now beginning to go public with his group's findings, briefing officials in Congress and the White House, as well as NASA advisory

\section{Infrared observatory prepares for lift-off}

Munich. The Infrared Space Observatory (ISO) is to be launched from Kourou, French Guiana, by the European Space Agency (ESA) this weekend. The observatory's RitcheyChretien-type telescope (right), which has a focal length of 9 metres and an aperture of $\mathbf{0 . 6}$ metres diameter, will turn its sights on some of the quarterof-a-million point sources of infrared radiation catalogued by IRAS, the joint UK/Dutch/US Infrared Astronomical Satellite, which scanned the infrared sky in 1983.

ISO's high sensitivity will give astrophysicists the opportunity to glean fundamental information about the formation of stars and solar systems. ISO will also search for the Universe's 'missing mass' - the difference between the theoretical mass of

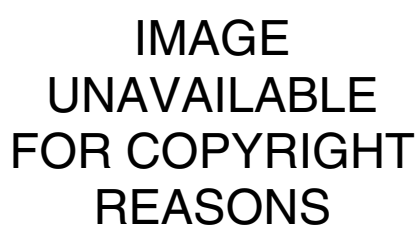

the Universe deduced from gravitational calculations and what can be seen in the visible light range. groups, on the plan's broad outlines.

The new institutes, selected through competitive bidding, would receive their core funding from NASA; existing NASA centres would provide "services and support" although what that means has not yet been spelled out. Not surprisingly, the institutes would be encouraged to seek outside funding and become as self-sufficient as possible. To that end, they would retain intellectual property from any research.

The Diaz team began and ended with the same list of 11 institutes proposed by another NASA review team earlier this year. According to Diaz himself, it agreed that a biomedical research institute affiliated with the Johnson Space Center (JSC) in Houston should be the first one established, perhaps by early next year.

The rest are in "various stages of readiness", he says. Three - a Goddard Institute for Space Studies in New York, a Global Hydrology and Climate Center at the Marshall Space Flight Center in Alabama, and an Astromaterials Institute at Johnson could be created by simply modifying existing relationships.

Three others need to be "further defined", according to the Diaz report. These are institutes for microgravity and space science at Marshall and an Atmospheric Sciences Institute at the Langley Research Center in Virginia. And two more - a space power and propulsion institute at the Lewis Research Center in Cleveland, Ohio, and the National Space Science Data Center, at Maryland's Goddard Space Flight Center should be reconsidered altogether, because "the model developed for other institutes is not applicable" to them.

The two remaining institutes - for astrobiology (Ames Research Center) and microgravity studies (Lewis) - are also problematic, as Congress might have to pass new laws to clear up thorny employment issues. These include the transfer of pensions and other benefits for government scientists who move to the private sector.

Another issue to be resolved concerns restrictions on where and how ex-government employees can work. NASA officials have already begun talking to congressional committees about passing "legislative relief". Without it, NASA scientists could lose benefits if they move to an institute.

But Diaz points out that the institutes should not be seen as a placement service for redundant government scientists. "The staffing of these institutes ought to be totally at the discretion of the institute management," he says, adding that NASA should not play a role in choosing who gets hired.

Tony Reichhardt 